\title{
Acremonium kiliense Infection in a Child With Chronic Granulomatous Disease
}

\author{
Antonio Carlos Pastorino ${ }^{1}$, Ulissis Pádua de Menezes $^{2}$, \\ Heloisa Helena de Souza Marques ${ }^{3}$, Marcelo G. Vallada ${ }^{3}$, \\ Vera Lúcia Cappellozi ${ }^{4}$, Eugénia Maria Grilo Carnide ${ }^{1}$ \\ and Cristina Miuki Abe Jacob ${ }^{5}$
}

\begin{abstract}
Allergy and Immunology Unit ${ }^{1}$, Department of Pediatrics; Fellow, Allergy and Immunology Unit ${ }^{2}$, Department of Pediatrics; Infectious Diseases Unit ${ }^{3}$, Department of Pediatrics; Department of Pathology ${ }^{4}$; Head, Allergy and Immunology Unit ${ }^{5}$, Department of Pediatrics; University of São Paulo; São Paulo, SP, Brazil
\end{abstract}

\begin{abstract}
Infection by unusual microorganisms can be one of the clinical manifestations of primary immunodeficiency (PID). We report on a four-month-old child with pneumonia caused by the fungus Acremonium kiliense as the first clinical manifestation of chronic granulomatous disease. We emphasize the importance of an active search for unusual organisms in immunodeficient patients, and a precise diagnosis and early institution of specific treatment against such microorganisms for the reduction of the morbidity and mortality of these patients.
\end{abstract}

Key Words: Infancy, immunodeficiency, chronic granulomatous disease, fungi, Acremonium.

Acremonium kiliense is a saprophytic fungus, characterized by light microscopy as a Gram-positive microorganism with septate hyphae, which presents slow growth in specific culture (Sabouraud agar, glucose and malt extract). This fungus can cause infections, such as dermatophytoses, kerion, onicomycoses, keratitis and mycetomas, in immunocompetent individuals, and pneumonia, arthritis, osteomyelitis, endocarditis, peritonitis, meningitis and sepsis in immunodeficient patients, especially in the presence of risk factors, such as prosthesis, catheters, immunosuppressive therapy and anatomic disorders [1-4].

Immunodeficient patients are more susceptible to infections. Among the immunodeficiencies, deficient phagocyte function can lead to recurrent pyogenic or fungal infections, causing an increase in morbidity and

Received on 10 September; revised 16 November 2005.

Address for correspondence: Dr. Antonio Carlos Pastorino, Allergy and Immunology Unit, Department of Pediatric, Universidade de São Paulo, São Paulo, Brazil. Rua Dr. João Batista Soares de Faria, 113 apto 141, Zip code: 02403-050, São Paulo, Brazil. Phone: 55.11.3069.8585. Fax: 55.11.6950.8481.

E-mail: antoniocp@icr.hcnet.usp.br or acpastorino@uol.com.br

The Brazilian Journal of Infectious Diseases 2005;9(6):529-534 (C) 2005 by The Brazilian Journal of Infectious Diseases and Contexto Publishing. All rights reserved. mortality. Chronic granulomatous disease (CGD) is a rare inherited phagocyte immunodeficiency, characterized by serious recurrent infections that can begin during the first year of life [5]. These patients are prone to pyogenic and fungal infections, such as cellulitis, folliculitis, lymphadenitis, osteomyelitis, lung infections, and skin and hepatic abscesses [6-9], caused by catalase-positive agents ( $S$. aureus, E. coli, Salmonella, Klebsiella, Pseudomonas, Serratia), mycobacteria and fungi (Aspergillus, Candida, Torulopsis). Other opportunistic agents, such as Nocardia asteroids, Francisella philomiragia, Acremonium kiliense, and Legionella gormanii, have been detected in patients with phagocyte disorders [1017].

We describe the clinical manifestations, etiological investigation and the therapeutic approach used for a CGD child with a persistent lung process since the $25^{\text {th }}$ day of life, which was found to be caused by Acremonium kiliense.

\section{Case Report}

A boy delivered by cesarean section without complications, weighing 3,350g, presented with cough, 
fever and tachypnea by the $25^{\text {th }}$ day of age. The initial chest radiography revealed hilar pneumonia in the right lung, which was treated with amikacin and oxacillin, with clinical improvement but with persistence of a lung image (Figure 1). He was referred to our institution for etiological investigation. Physical examination revealed persistent tachypnea, axillary and inguinal adenopathy ( 0.5 to $1 \mathrm{~cm}$ in diameter) and decreased murmur, rhonchi and inspiratory rales in the middle $1 / 3$ of the right hemithorax, without wheezing. The liver was palpable $1.5 \mathrm{~cm}$ below the right costal margin, without pain in the right upper quadrant.

A chest CT scan showed a large nodular image, with solid and cystic areas in the right lung (Figure 2). The lung biopsy, obtained three months after the onset of symptoms, showed a granulomatous process, with an area of intense necrosis, with the presence of septate hyphae (Figure 3). Ziehl-Neelsen staining was negative for BAAR and culture in Saboraud agar identified Acremonium kiliense, an opportunistic fungus. The patient was then referred to an immunologist to perform an immunological investigation, which revealed normal humoral, cellular and complement function (Table 1). PCR for HIV was negative. The Nitroblue Tetrazolium test (NBT) was zero. Genetic analysis revealed deficiency in the gp91 subcomponent of NADPHoxidase, confirming the diagnosis of X-linked CGD.

The child received itraconazole orally $(10 \mathrm{mg} / \mathrm{kg} / \mathrm{day})$ for six weeks, with progressive disappearance of symptoms and radiological image. He received subcutaneous gamma-interferon $\left(50 \mathrm{mg} / \mathrm{m}^{2}\right)$ three times a week, associated with prophylactic trimethoprimsulfamethoxazole.

\section{Discussion}

Bruton published the first description of primary immunodeficiency in 1952, with the identification of hypogammaglobulinemia in a child with recurrent infections. Since then, several primary immunodeficiencies (ID) have been described, with the following warning signs for their identification: two or more pneumonias in one year, eight or more episodes of otitis in one year, persistent thrush for more than two months after the first year of life, deep-seated or severe infection (meningitis, sepsis, osteoarthritis), recurrent giardiasis, respiratory allergy, autoimmune diseases, and clinical phenotype or a family history of immunodeficiency [5].

The Latin-American Group of Immunodeficiency Diseases (LAGID) carried out an epidemiological survey of primary immunodeficiencies involving 11 countries, including Brazil, adopting a recent classification for PID [15], and it detected 1,428 immunodeficient patients [18]. Humoral deficiency was the most prevalent $(58 \%)$, followed by cellular and combined deficiency (23\%), phagocyte deficiency $(9 \%)$, syndromes associated with granulocyte dysfunction (8\%), and complement deficiency (2\%).

Chronic granulomatous disease (CGD) is a rare immunodeficiency inherited as an X-linked or an autosomal recessive disorder, with a frequency of $1: 1,000,000$ in the US, 1:300,000 in Japan and $1: 160,000$ in Denmark. In general, the first clinical manifestation of CGD occurs before three years of age and $95 \%$ of the cases are diagnosed by five years [6]. Pyogenic and fungal infections are frequent, and they involve the skin, lymph nodes, lungs, liver, bone, and the gastrointestinal or urinary tract [17]. Few cases are diagnosed during adulthood, and they usually involve the most common recessive form (p47-phox subcomponent deficiency) [6,9]. The relative frequencies of the different patterns of genetic CGD inheritance have been described by Curnutte [18]. Xlinked inheritance is observed in approximately $65 \%$ of patients; it results from mutation in the gene encoding the gp91-phox subunit of the cytochrome $b_{558}$ component. The remaining $35 \%$ of CGD patients have autosomal recessive disease due to mutations in the genes encoding the remaining three oxidase components, i.e., p22-phox (chromosome 16), p47phox (chromosome 7) and p67-phox (chromosome 1).

CGD was first described in 1957, in a patient in which the defect of one of two components of NADPH oxidase caused deficient superoxide $\left(0_{2}^{-}\right)$and hydrogen peroxide $\left(\mathrm{H}_{2} \mathrm{O}_{2}\right)$ production, resulting in disturbances in 
Figure 1. Chest radiography revealing hilar pneumonia.
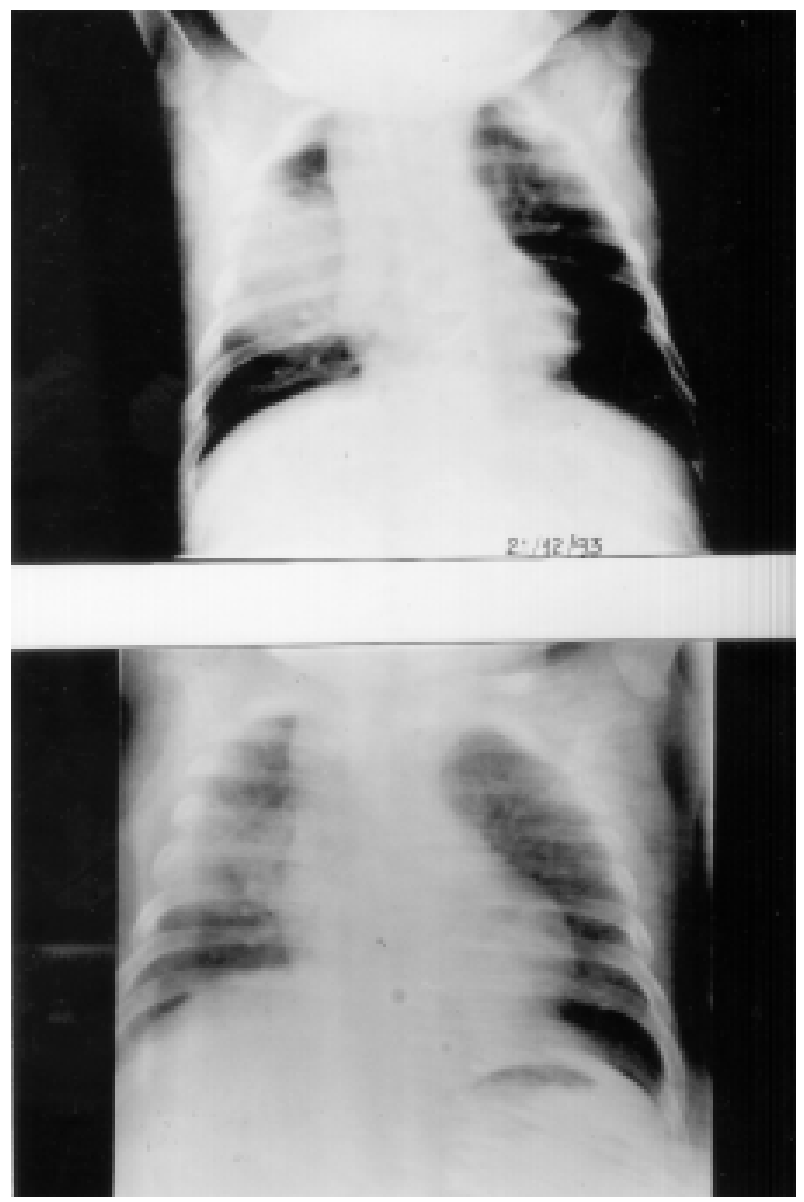

Figure 2. Chest computed tomography showing a large nodular image.
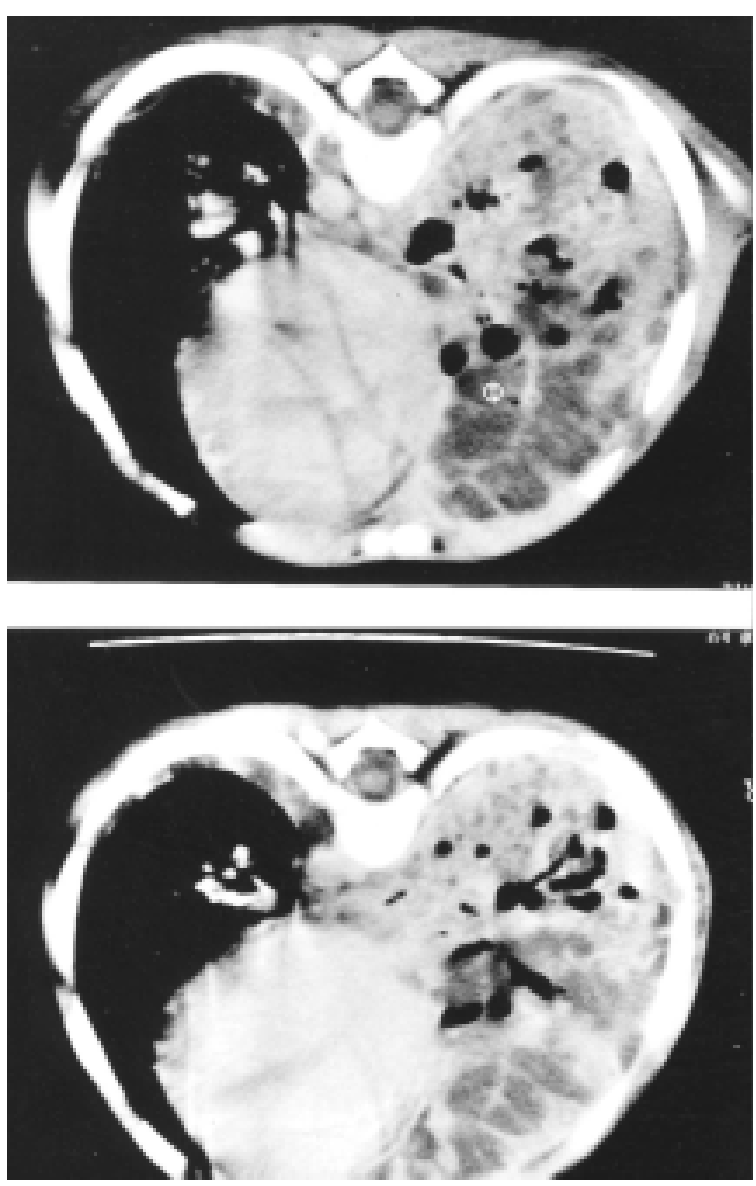

Figure 3. Lung biopsy showing septate hyphae

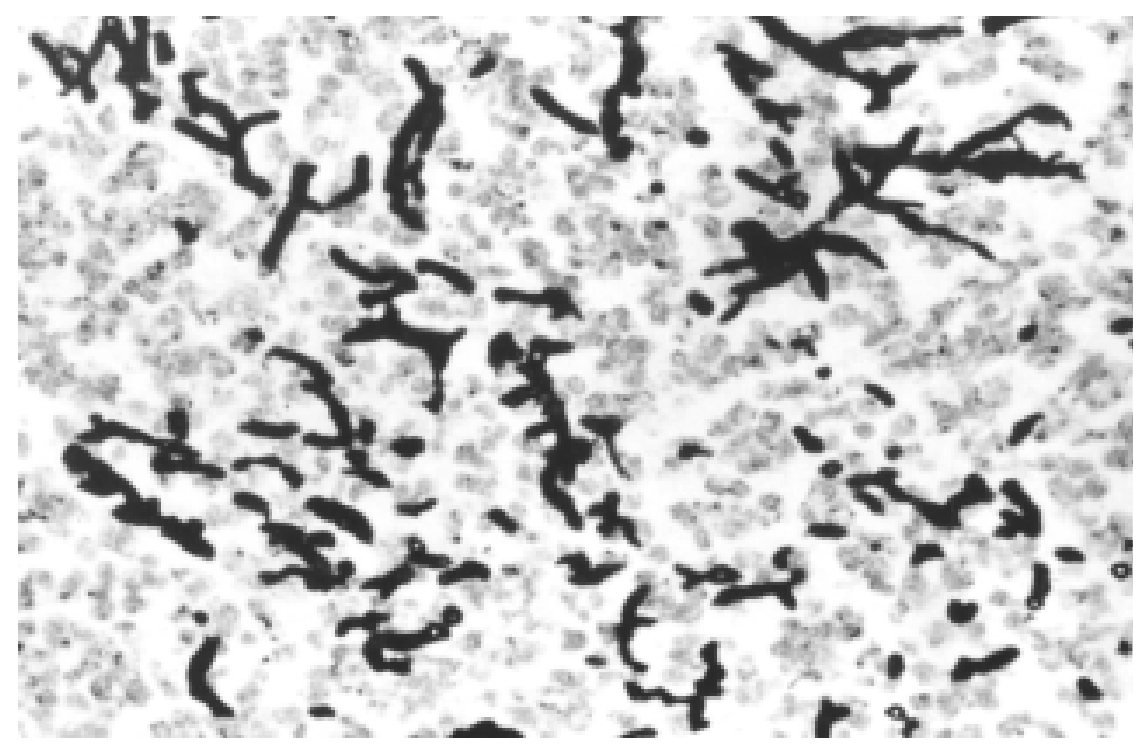


Table 1. Immunological evaluation of a child with chronic granulomatous disease

\begin{tabular}{lll}
\hline Data & Value & Reference \\
\hline $\mathrm{IgG}(\mathrm{mg} / \mathrm{dL})$ & 1,290 & $736 \pm 243^{1}$ \\
$\mathrm{IgA}(\mathrm{mg} / \mathrm{dL})$ & 170 & $40 \pm 24^{1}$ \\
$\mathrm{IgM}(\mathrm{mg} / \mathrm{dL})$ & 301 & $60 \pm 34^{1}$ \\
$\mathrm{CD}_{4}(\mathrm{absolute}$ count $)$ & 1,791 & $1,500-5,000^{2}$ \\
$\mathrm{CD}_{8}(\mathrm{absolute}$ count$)$ & 741 & $500-1,600^{2}$ \\
$\mathrm{CD}_{4} / \mathrm{CD}_{8}$ & 2.42 & $1.7-3.9^{2}$ \\
Complement component & & \\
$\quad \mathrm{C} 3(\mathrm{mg} / \mathrm{dL})$ & 111 & $78.1-112.9$ \\
$\quad \mathrm{C} 4(\mathrm{mg} / \mathrm{dL})$ & 30 & $15-45$ \\
NBT (stimulate to PMA) & & $>90 \%$ \\
$\quad$ Patient & 0 & $>90 \%$ \\
$\quad$ Father & 40 & \\
\hline
\end{tabular}

\footnotetext{
${ }^{1}$ Normal value in Brazilian children - Naspitz et al. J Ped 1982; 52:121-126

${ }^{2}$ Comas-Bitter et al. J Pediatr 1997; 130:388-398.
}

the oxidative metabolism of phagocytes [5]. The diagnosis of CGD is made by a demonstration of defective microbicidal activity in neutrophils. One of the most frequent tests used is the nitroblue tetrazolium (NBT) reduction test [15], which detects the reduction of soluble yellowish dye to formazan, a dark blue pigment. This reaction can be stimulated by phorbol myristate acetate or E. coli lipopolysaccharide, which promote an increase in the oxidative burst in $90 \%$ to $100 \%$ of normal neutrophils. The neutrophils of CGD patients do not produce the anion superoxide, being unable to reduce NBT. Mothers of CGD patients, the inheritance of which is X-linked, show intermediate positivity of the NBT reaction (around 40\%), and a diagnosis can be made during the prenatal period by applying the NBT test from the $16^{\text {th }}$ to the $20^{\text {th }}$ week of gestation.

Acremonium kiliense infection can present as a cutaneous papular eruption, associated or not with other clinical signs, denoting its low pathogenicity. There are few case reports of infections involving the skin, esophagus or heart. This fungus is susceptible to nystatin, ketoconazole, itraconazole and amphotericin $\mathrm{B}$; however, recent reports have described ketoconazole and amphotericin $B$ resistance $[3,4]$. The diagnosis can be confirmed by detecting the agent in blood or other fluids, or by a tissue biopsy $[19,20]$.

The clinical history of our patient began during the neonatal period, with cough, tachypnea, and a nodular hilar opacification in a chest x-ray. The patient was treated with the usual antibiotics, with improvement of general symptoms, but the nodular image persisted.

Various infectious agents, such as $S$. aureus, Nocardia, Mycobacterium and Aspergillus, can cause isolated nodular lesions. In children, nodular lesions are rarely related to neoplasms or viral infections, which normally present micro-nodular or interstitial patterns. Therefore, a systematized approach is necessary in these cases, including pulmonary fluid and serial blood cultures, a chest CT scan, and in some cases, a lung biopsy to obtain samples for culture and histological analysis. In this case, Acremonium kiliense was only diagnosed by culture of a biopsy specimen.

This case shows the necessity to search for ID in patients with precocious infection, prolonged or unusual findings caused by uncommon or opportunistic microorganisms, precocious death or immunodeficiency in relatives, syndromes or diseases associated with immunodeficiency and persistent lymphopenia. 
Laboratory screening includes a complete blood count and $B$ and $T$ cell subpopulation counts, determination of serum immunoglobulin level, a delayed hypersensitivity cutaneous test, serum complement evaluation, NBT test, and HIV screening, in addition to a chest X-ray for evaluation of the presence of a thymic shadow [15].

The specific treatment of CGD consists of the control of the infectious processes, broad-spectrum antibiotics for commonly related agents and reevaluation after agent isolation. The early and prolonged use of antimicrobial or antifungal agents is very important for improved outcome of CGD patients. A surgical approach is necessary in cases that tend to present abscess formation or obstructive granulomas $[9,10,21,22]$. The continuous use of prophylactic therapy with trimethoprim-sulfamethoxazole has reduced the number of serious infections and has increased patient survival [14,23,24]. Gammainterferon has been used by CGD patients with immunological problems. This drug acts as a macrophage-activating factor and its administration in vitro and in vivo has provoked an increase in both the production of oxygen intermediates and the killing of bacterial and protozoal pathogens. Various studies have shown its effect on CGD, decreasing the incidence of complications of serious infectious diseases and the duration of hospitalization [23-25]. Bone marrow transplant is another therapeutic option in the treatment of CGD. The limitations and inherent risks of bone marrow transplants should be considered, except in HLA identical twins, for which the procedure allows cure in some cases [23,24,26]. Promising experiments with the use of gene therapy in CGD have been made in rare cases [24,26,27].

Although CGD is very rare ID, an early diagnosis and a specific approach are essential to reduce the morbidity and mortality of these patients.

\section{Acknowledgment}

We are indebted to Dr. A. Condino-Neto for genetic analysis of our patient (Department of Pediatric-Faculty of Medical Sciences - UNICAMP, Campinas, São
Paulo, Brazil) and Dr. Carlos da Silva Lacaz, for isolation of the fungus (Head of Laboratory of Mycology, Tropical Medicine Institute, São Paulo, Brazil).

\section{References}

1. Lopes J.O., Kolling L.C., Neumaier W. Kerionlike lesion of the scalp due to Acremonium kiliense in a noncompromised boy. Rev Inst Med Trop São Paulo 1995;37:358-65.

2. Lacaz C.S., Porto E., Carneiro J.J., et al. Endocardite em prótese de dura-mater provocada pelo Acremonium kiliense. Rev Inst Med Trop São Paulo 1981;23:274-9.

3. Simon G., Rakoczy G., Galgoczy J., et al. Acremonium kiliense in oesophagus stenosis. Mycoses 1991;34:257-60.

4. Brown N.M., Blundell E.L., Chown S.R., et al. Acremonium infection in a neutropenic patient. J Infect 1992;25:73-6.

5. Stiehm E.R. New and Old Immunodeficiencies. Pediatr Res 1993;33(suppl):S2-S8.

6. Liese J.G., Jendrossek V., Jansson A., et al. Chronic granulomatous disease in adults. Lancet 1996;347:220-3.

7. Grumach A.S., Jacob C.M.A., Stolf N.G., et al. Pericardite constrictiva como complicação de doença granulomatosa crônica na infância. Rev Hosp Clin Fac Med São Paulo 1987;42:30-2.

8. Ahlin A., De Boer M., Ross D., et al. Prevalence, genetics and clinical presentation of chronic granulomatous disease in Sweden. Acta Paediatr 1995;84:1386-94.

9. Rosh J.R., Tang H.B., Mayer L., et al. Treatment of intractable gastrointestinal manifestations of chronic granulomatous disease with cyclosporine. J Pediatr 1995; $126: 143-5$.

10. Mouy R., Veber F., Blanche S., et al. Long-term itraconazole prophylaxis against Aspergillus infections in thirty-two patients with chronic granulomatous disease. J Pediatr 1994; 125:998-1003.

11. Gonzales L.A., Kiff J.E., Umetsu D.T. A three-week-old infant with invasive pulmonary aspergillosis. Ann Allergy 1994;73:392-400.

12. Ohga S., Ikeuchi K., Kadoya R., et al. Intrapulmonary Mycobacterium avium infection as the first manifestation in chronic granulomatous disease. $\mathrm{J}$ Infect 1997;34:147-50.

13. Malmvall B.E., Follin P. Successful interferon-gamma therapy in a chronic granulomatous disease (CGD) patient suffering from Staphylococcus aureus hepatic abscess and invasive Candida albicans infection. Scand J Infect Dis 1993;25:61-6. 
14. Shetty A.K., Arvin A.M., Gutierrez K.M. Nocardia farcinica pneumonia in chronic granulomatous disease. Pediatrics 1999; 104:961-4.

15. Report of a Who Scientific Group: Primary immunodeficiency disease. Clin Exp Immunol 1995;99:134.

16. Zelazko M., Carneiro-Sampaio M., Cornejo de Luigi M., et al. Primary immunodeficiency diseases in Latin America: first report from eight countries participating in the LAGID. Latin American Group for Primary Immunodeficiency Disease. J Clin Immunol 1998; 18:161-6.

17. Dohil M., Prendiville J.S., Crawford R.I., Speert D.P. Cutaneous manifestations of chronic granulomatous disease. A report of four cases and review of the literature. J Am Acad Dermato 1997;36:899-907.

18. Curnutte J.T. Chronic Granulomatous Disease: the solving of clinical riddle at molecular level. Clin Immunol Immunopathol 1993;67:S2-S15.

19. Lau Y.L., Yuen K.Y., Lei C.W., Chan C.F. Invasive Acremonium falciforme infection in a patient with severe combined immunodeficiency. Clin Infect Dis 1995;20:197-8.

20. Frankel L.R., Smith D.W., Lewiston N.J. Broncoalveolar lavage for diagnosis of pneumonia in the immunocompromised child. Pediatrics 1988;81:785-8.

21. Casson D.H., Riordan F.A., Ladusens E.J. Aspergillus endocarditis in chronic granulomatous disease. Acta Paediatr 1996;85:758-9.

22. Eckert J.W., Abramson S.L., Starke J., Brandt M.L. The surgical implications of chronic granullomatous disease. Am J Surg 1995; 169:320-3.

23. Fischer A., Segal A.W., Seger R., Weening R.S. The management of chronic granulomatous disease. Eur J Pediatr 1993;152:896-9.

24. Ballow M., Nelson R. Immunopharmacology: immunomodulation and immunotherapy. JAMA 1997;278:2008-17.

25. Curnutte J.T. Conventional versus Interferon-g Therapy in Chronic Granulomatous Disease. J Infect Dis 1993; 167(suppl):S8-S12.

26. Akioka S., Itoh H., Ueda I., et al. Donor lymphocyte infusion at unstable mixed chimerism in an allogeneic $\mathrm{BMT}$ recipient for chronic granulomatous disease. Bone Marrow Transplant 1998;22:609-11.

27. Zentilin L., Tafuro S., Serra C., et al. Gene therapy of chronic granulomatous disease (CGD) by gene transfer into hematopoietic stem cells. Ann Ist Super Sanit 1998;34:447-55. 